OPEN ACCESS

Edited by:

Llewellyn Ellardus Van Zyl, North-West University, South Africa

Reviewed by: Helen Henrietta Egan Birmingham City University, United Kingdom

Federica Cavazzoni, University of Milano-Bicocca, Italy

*Correspondence: Jing-Xu Chen chenjx1110@163.com

Specialty section: This article was submitted to Health Psychology, a section of the journal Frontiers in Psychology

Received: 26 June 2020 Accepted: 18 September 2020 Published: 09 October 2020

Citation:

Hu N, Li Y, He S-S, Wang L-L, Wei Y-Y, Yin L and Chen J-X (2020) Impact of the Family Environment on the Emotional State of Medical Staff

During the COVID-19 Outbreak: The Mediating Effect of Self-Efficacy.

Front. Psychol. 11:576515.

doi: 10.3389/fpsyg.2020.576515

\section{Impact of the Family Environment on the Emotional State of Medical Staff During the COVID-19 Outbreak: The Mediating Effect of Self-Efficacy}

\author{
$\mathrm{Na} \mathrm{Hu}{ }^{1}$, Ying $\mathrm{Li}^{2}$, Su-Shuang He', Lei-Lei Wang ${ }^{1}$, Yan-Yan Wei ${ }^{1}$, Lu Yin ${ }^{1}$ and \\ Jing-Xu Chen ${ }^{1 *}$
}

${ }^{1}$ Beijing Huilongguan Hospital, Peking University Huilongguan Clinical Medical School, Beijing, China, ${ }^{2}$ Beijing Children's Hospital, Capital Medical University, National Center for Children's Health, Beijing, China

During the outbreak of the coronavirus disease 2019 (COVID-19), the medical staff was facing severe work pressure, which led to a negative emotional state. The purpose of this study was to explore the relationship between the family environment and the emotional state of the medical staff members during the COVID-19 outbreak. Due to the importance of self-efficacy in regulating mental health, the mediating role of self-efficacy in the association between family environment and emotional state was also explored. A cross-sectional survey was performed, using an online questionnaire, on 645 medical staff who participated in the epidemic prevention and control tasks during the COVID-19 outbreak in Beijing. Family environment, self-efficacy, anxiety, and depressive symptoms were measured by the Family Environment Scale-Chinese Version (FES-CV), the General Self-Efficacy Scale (GSES), the Generalized Anxiety Disorder Scale-7 (GAD-7), and the Patient Health Questionnaire-9 (PHQ-9), respectively. Correlation analysis and mediating effect analysis were used to explore the relationships between them. First, a higher prevalence of anxiety (39\%) and depressive (33\%) symptoms were confirmed among the medical staff. Second, the symptoms of anxiety and depression were negatively correlated with the dimensions of cohesion and expressiveness and positively correlated with the dimensions of conflict in the FES-CV scale. Third, self-efficacy significantly mediated the association between the family environment and anxiety symptoms $(P<0.001)$ as well as the family environment and depressive symptoms $(P<0.001)$. These findings show that a negative family environment was the main predictor of symptoms of anxiety and depression in the medical staff during the COVID-19 outbreak. Furthermore, we found that self-efficacy played a critical mediating role between the family environment and the symptoms of anxiety and depression. Our study also indicates that improvements in the family environment benefit the mental health care of the medical staff, and high self-efficacy enhances this effect.

Keywords: COVID-19, medical staff, family environment, self-efficacy, anxiety symptoms, depression symptoms 


\section{INTRODUCTION}

The outbreak of coronavirus disease 2019 (COVID-19) continues to attract worldwide attention (Wang et al., 2020). To date, COVID-19 cases have been confirmed in more than 200 countries around the world, and it has become a public health emergency of international concern. Many people who have directly faced this large-scale public crisis, especially the medical staff involved in the prevention and control of this epidemic, showed anxiety symptoms (Huang et al., 2020). They faced a high risk of getting infected at their workplace and the possibility of their family members at home getting infected through them (Xiang et al., 2020). Medical staff working in a high-pressure environment suffer from psychological problems, especially anxiety and depression (Kang et al., 2015; Wang et al., 2020). Although guidelines on the care of the mental health issues in medical staff have been issued in China (Kang et al., 2020), some of the staff refused to receive mental health care (Chen et al., 2020).

It has been reported that the incidence of anxiety and depression was high among the medical staff during the outbreak of COVID-19, with prevalence rates of anxiety and depressive symptoms being $44.6 \%$ and $50.4 \%$, respectively (Lai et al., 2020). Due to the stigma around mental health problems in China (Bai et al., 2004), many members of the medical staff community were reluctant to accept professional psychological help (Chen et al., 2020). However, they preferred to seek help from their family members. Some medical staff was far away from their families because of the fear of infection, and they were reluctant to have close contact with them. Others were isolated and cannot return home for a long time (Raven et al., 2018). It has shown that family support is very important for medical staff involved in epidemic prevention (Mohindra et al., 2020). However, there has been no research on how family members can help medical professionals suffering from mental health issues and what kind of family environment can be useful in relieving negative emotions in these individuals during an epidemic. The family, which is the basic social unit, may affect the mental health of family members (Cheng et al., 2017). In Chinese culture, family relations are highly valued, and family is a very important support system (Poulin et al., 2012). It means that the importance of family is the core feature for most Chinese people. Previous studies have shown that the family environment can directly affect the emotions in family members, especially the dimension of cohesion (Harris and Zakowski, 2003; Burnett et al., 2017), expressiveness (Luebbe and Bell, 2014), and conflict (Yap et al., 2014; Yap and Jorm, 2015; Fosco et al., 2016). However, whether the family environment has an effect on the mental health of medical staff during the epidemic is still not clear.

Self-efficacy refers to an individual's judgment about his or her ability to complete a certain task successfully, and it reflects the self-confidence of an individual to cope with various difficulties and setbacks in life (Tang et al., 2019). Previous research has shown a positive correlation between the family environment and self-efficacy (Mahmoudi, 2012). Individuals with a better family environment were shown to be more likely to have higher levels of self-efficacy (Hemati et al., 2020). For example, individuals can freely communicate with family members, express more about themselves, and have a frequent high contact of intimacy with other family members, which will lead to a high level of selfefficacy (Hemati et al., 2020). Studies show that increasing selfefficacy is an essential aspect of the psychological intervention to protect the mental health of individuals (Caldwell et al., 2009). It seems that the higher the self-efficacy in an individual, the better the mental health (Sebastian, 2013; Jiang et al., 2020). High self-efficacy can improve an individual's mental health (Bandura, 2012). However, a low level of self-efficacy harms a person's psychological well-being (Cieslak et al., 2008; Sachs-Ericsson et al., 2011). Importantly, studies have shown that self-efficacy is one of the critical factors that modulate an individual's emotions, especially feelings of anxiety and depression (Bandura et al., 1982; Kanfer and Zeiss, 1983; Cybulski et al., 2017; Schönfeld et al., 2019). These studies suggested that higher levels of selfefficacy are associated with lower levels of feelings of anxiety and depression. During the outbreak of SARS, medical staff with low self-efficacy often had a higher fear of the epidemic, which was positively correlated with their poor mental health status (Ho et al., 2005). Self-efficacy can predict the significant difference in mental health during the epidemic. The lower the self-efficacy, the worse the mental health status (Yildırım and Güler, 2020). It has been found that lower psychological stress among dentists during the COVID-19 epidemic is associated with being in a stable relationship and having a higher sense of self-efficacy (Shacham et al., 2020). It suggests that family relationships and self-efficacy during the epidemic may both affect the mental health of medical staff. The partial mediating role of self-efficacy in some psychological trait relationships has been supported by relevant research (Haj-Yahia et al., 2019). Indeed, it has been found that self-efficacy was a mediator for the association of daily stress and mental health (Schönfeld et al., 2019). However, there has been no study focusing on the relationship between family environment, self-efficacy, and the emotional state of medical professionals during an epidemic. The relationship between family environment, self-efficacy, and depression and anxiety, and whether the influence of family environment on anxiety and depression is regulated by selfefficacy needs to be further studied.

Therefore, the purpose of this study was to further explore the direct and indirect impact of the family environment on symptoms of anxiety and depression among the medical staff involved in controlling the epidemic. When examining the indirect effects, we took self-efficacy as an intermediary variable. Mediating effect analysis was performed to explore the role of self-efficacy in the relationship between family environment and symptoms of anxiety and depression. Based on our findings, we provide viable strategies for the family based psychological intervention of the medical staff during an epidemic that will help to improve our psychological crisis intervention system.

\section{MATERIALS AND METHODS}

\section{Participants}

This research was a cross-sectional study using the convenience sampling method to collect survey results through an online 
questionnaire. The online survey was conducted in Beijing from February 28, 2020 to March 9, 2020. Inclusion criteria for the study were as follows: (1) Chinese, working in Beijing; (2) 1865 years old; (3) medical staff including doctor or nurse involved in COVID-19 epidemic prevention and control; and (3) has read and agreed to the online informed consent. The protocol of this study was approved by the Ethics Committee of the Beijing Huilongguan Hospital.

\section{Study Instruments The Family Environment Scale-Chinese Version (FES-CV)}

This scale was based on the Family Environment Scale (FES) developed by Moss (Moos and Moos, 1994), which was translated into Chinese by Wang et al. (Wang et al., 1999). The scale has 90 entries in total, including 10 dimensions (cohesion, expressiveness, conflict, independence, achievement orientation, intellectual-cultural orientation, active-recreational orientation, moral-religious emphasis, organization, and control), with nine entries for each dimension. Each entry has a true and false option. The higher the score of a particular dimension, the more prominent the characteristics of the family in that aspect. The scores of conflict and control were negatively correlated with the family environment, whereas others positively correlated with the family environment. This scale has been shown to have good structural, content, and external validity when applied to the Chinese population (Phillips et al., 1998). In this study, we selected three dimensions of this scale that were closely related to emotions investigated in previous studies: cohesion, expressiveness, and conflict (Harris and Zakowski, 2003; Burnett et al., 2017).

\section{The General Self-Efficacy Scale (GSES)}

This scale was developed by German psychologist Schwarzer (Schwarzer, 1995), which was translated and revised for the Chinese version by Wang et al. (Wang et al., 2001). The scale comprises of 10 items with four answer options, and the answer options range from 1 (not at all true) to 4 (completely true). Higher scores mean higher levels of self-efficacy; a score of 1.02.0 means low level, 2.1-3.0 means medium level, and 3.1-4.0 means a high level of self-efficacy. The revised scale has been shown to have excellent reliability and validity in the Chinese population (Wang et al., 2001). The Cronbach's alpha of this scale is 0.87 , the retest reliability is 0.83 , and the correlation coefficient between the 10 items and the total scale score is $0.60-0.771$.

\section{The Generalized Anxiety Disorder Scale-7 (GAD-7)}

This scale was developed by Spitzer et al. (Spitzer et al., 2006). Previous research demonstrated that the Chinese version of GAD-7 has good reliability and validity, and the sensitivity and specificity of this version were 0.86 and 0.95 , respectively (Huang et al., 2019). This scale is composed of seven items, and each item has a $0-3$ points scale. The total score range is $0-21$ points; $0-4$ for no anxiety, 5-9 for mild anxiety, 10-14 for moderate anxiety, and more than 15 for severe anxiety.

\section{The Patient Health Questionnaire-9 (PHQ-9)}

The scale was developed based on the fourth edition of the Diagnostic and Statistical Manual of Mental Disorders (Kroenke et al., 2001). We used the Chinese version of this scale. This scale is composed of nine items, and each item has a 0-3 points scale. The symptom severity is determined by the total score, with 59 being mild, 10-14 being moderate, 15-19 being moderately severe, and 20-27 being severe. Cronbach's alpha of the PHQ-9 in the Chinese population is 0.86 , and the retest reliability is 0.86 , which indicates that this test has excellent reliability and validity (Wang et al., 2014).

\section{Statistical Analysis}

All of the analyses were performed using SPSS for Windows 23.0. We reported means and standard deviations for continuous variables showing normal distribution and frequencies and proportions for categorical variables. The original scores of the dimensions of conflict in FES-CV were not normally distributed and were presented as medians and quartiles. A chisquared test was used to test the relationship between the demographic data of the participants and their anxiety and depressive symptoms. The study participants were grouped based on whether they showed/did not show anxiety or depressive symptoms. The inter-group comparison of the scores of FESCV and GSES was carried out using the independent sample $t$-test and the independent sample Kruskal-Wallis test. Spearman correlations were calculated to determine the relationships between the scores of the various scales. We categorized the family environment (cohesion, expressiveness, and conflict) as an independent variable, anxiety and depression symptoms as dependent variables, and self-efficacy as an intermediary variable. After controlling for demographic variables, the direct, indirect, and total effects of the family environment on the symptoms of anxiety and depression were examined. The mediation analysis was run on the PROCESS macro for SPSS (Preacher and Hayes, 2004), using 5,000 bootstrap samples for bias correction and to establish 95\% confidence intervals. All of the tests were twotailed, and the significance level was set at $p<0.05$.

\section{RESULTS}

The medical staff involved in this study mainly includes two groups. One is the staff of the hospital involved in treating patients infected with COVID-19; the other is the staff at the isolation point, whose main task is nucleic acid testing and medical services for the quarantined personnel. A total of 653 medical staff members completed the online questionnaire, out of which six individuals did not complete the basic information, and two took more than $5 \mathrm{~min}$ to answer the questionnaire. Thus, 645 medical staff members participated in the study, of which 485 (75\%) were women, and 160 (25\%) were men, aged 21-65, with an average age of $35.88 \pm 8.64$. Most of the participants were under $40(75 \%)$, had a bachelor's degree (61\%), were married (73\%), and were living with their families (83\%). Among these participants, 251 (39\%) had anxiety symptoms, and 215 (33\%) had depressive symptoms. The symptoms of anxiety and 
depression were closely related to the gender of the medical staff and whether they lived with their family members or not. The prevalence rate of anxiety and depression symptoms was higher in women $\left(X^{2}=9.25, p=0.002 ; X^{2}=4.09, p=0.043\right)$ and in those who did not live with their families $\left(X^{2}=5.38, p=0.02 ; X^{2}=4.35\right.$, $p=0.037$ ) (Table 1).

We divided the participants into two groups: one group with anxiety symptoms (GAD-7 score > 4) and the other group without anxiety symptoms (GAD-7 score $\leq 4)$. We then investigated the significance of the differences in the scores of the two groups for the FES-CV and GSES scales. Next, the participants were divided into two groups according to whether they had depressive symptoms or not (depressive symptoms: PHQ-9 score $>$ 4; no depressive symptoms: PHQ-9 score $\leq 4$ ). Like the anxiety symptoms, we investigated the significance of the difference between the scores of FES-CV and GSES scales in the two groups. The results, which show the significant differences among groups, are shown in Table 2.

Next, we used correlation analysis to determine the correlation between the scores of each scale. The results showed that there were statistically significant relationships between the anxiety and depressive symptoms of medical staff, their family environment, and their sense of self-efficacy. Anxiety and depressive symptoms showed a significant positive correlation with the dimension of conflict in FES-CV scale $(r=0.29, p<0.001 ; r=0.25, p<0.001)$, and a significant negative correlation with the dimension of cohesion $(r=-0.31, p<0.001 ; r=-0.38, p<0.001)$, expressiveness $(r=-0.23, p<0.001 ; r=-0.30, p<0.001)$, and self-efficacy $(r=-0.25, p<0.001)$. More specifically, individuals with bad family environments and low self-efficacy were more

TABLE 1 | Demographic characteristics of the study participants $(N=645)$.

\begin{tabular}{|c|c|c|c|c|c|}
\hline \multirow[t]{2}{*}{ Variables } & \multirow{2}{*}{$\begin{array}{c}\text { Total } \\
N=645\end{array}$} & \multicolumn{2}{|c|}{ Anxiety symptoms } & \multicolumn{2}{|c|}{ Depressive symptoms } \\
\hline & & $x^{2}$ & $\boldsymbol{P}$ & $x^{2}$ & $P$ \\
\hline Gender & & 9.25 & 0.002 & 4.09 & 0.043 \\
\hline Male & 160 & & & & \\
\hline Female & 485 & & & & \\
\hline Age & & 6.30 & 0.098 & 5.97 & 0.113 \\
\hline$\leq 30$ & 208 & & & & \\
\hline $31-40$ & 274 & & & & \\
\hline $41-50$ & 119 & & & & \\
\hline$\geq 51$ & 44 & & & & \\
\hline Education & & 2.71 & 0.607 & 2.39 & 0.664 \\
\hline $\begin{array}{c}\text { Below } \\
\text { bachelor's }\end{array}$ & 126 & & & & \\
\hline Bachelor's & 396 & & & & \\
\hline $\begin{array}{l}\text { Master's } \\
\text { or higher }\end{array}$ & 123 & & & & \\
\hline $\begin{array}{l}\text { Marital } \\
\text { status }\end{array}$ & & 1.55 & 0.213 & 0.96 & 0.326 \\
\hline Single & 176 & & & & \\
\hline Married & 496 & & & & \\
\hline $\begin{array}{l}\text { Live with } \\
\text { family }\end{array}$ & & 5.38 & 0.02 & 4.35 & 0.037 \\
\hline Yes & 535 & & & & \\
\hline No & 110 & & & & \\
\hline
\end{tabular}

likely to show symptoms of anxiety and depression. Besides, selfefficacy positively correlated with the dimension of cohesion and expressiveness and negatively associated with the dimension of conflict (Table 3).

After controlling for demographic variables, we examined the mediating effects of self-efficacy (Figure 1). Self-efficacy was significantly associated with the symptoms of anxiety and depression. It significantly mediated the association between the family environment and anxiety symptoms $(\beta=-0.12$; $95 \% \mathrm{CI},-0.19$ to $-0.06 ; \beta=-0.10 ; 95 \% \mathrm{CI},-0.16$ to -0.05 ; and $\beta=0.06 ; 95 \% \mathrm{CI}, 0.02$ to 0.11 ). Similarly, it mediated the association between family environment and the depressive symptoms $(\beta=-0.09 ; 95 \% \mathrm{CI},-0.16$ to $-0.03 ; \beta=-0.08$; $95 \% \mathrm{CI},-0.14$ to -0.03 ; and $\beta=0.06$; $95 \% \mathrm{CI}, 0.02$ to 0.11 ). When controlling for self-efficacy, the association between the family environment and anxiety symptoms were still significant $(\beta=-0.62, p<0.001 ; \beta=-0.52, p<0.001 ;$ and $\beta=0.55$, $p<0.001)$ and similarly for family environment and depressive symptoms $(\beta=-0.87, p<0.001 ; \beta=-0.84, p<0.001$; $\beta=0.55, p<0.001)$. Thus, self-efficacy partly mediated the relationship between the family environment and the symptoms of anxiety and depression.

\section{DISCUSSION}

In the current study, we conducted an online questionnaire survey of some medical staff involved in COVID-19 prevention and control in hospitals and isolation sites in Beijing. We found that a considerable proportion of medical professionals had anxiety (39\%) and depressive symptoms (33\%), as noted in previous studies (Huang et al., 2020; Lai et al., 2020). Moreover, our results showed that the family environment of medical staff and their symptoms of anxiety and depression during the epidemic were closely related to self-efficacy, and self-efficacy partly mediated the relationship between the family environment and the symptoms of anxiety and depression.

In this present study, we found that the self-efficacy of male medical staff was significantly higher than that of female medical staff $(t=3.245, p=0.001)$. However, the symptoms of anxiety $(p<0.001)$ and depression $(p=0.002)$ during COVID-19 were significantly lower than that of female medical staff, which was consistent with previous research results. For example, it showed that female medical workers experience higher levels of anxiety, depression, and distress during COVID-19 (Lai et al., 2020). It also reported that the self-efficacy of male medical staff is significantly higher than that of female medical staff (Tang et al., 2019). It should also be noted that medical staff who did not live with their families were more likely to have symptoms of anxiety and depression during the epidemic. Thus, our study suggests that we should pay more attention to such medical staff and provide them psychological intervention. This observation also indicates that the family plays a certain role in regulating negative emotions. Furthermore, our study showed a close relationship between the family environment of the medical staff and their symptoms of anxiety and depression. The medical staff members with low cohesion and expressiveness, as well as high conflict in 
TABLE 2 | Differences in scores of the family environment and self-efficacy under different emotions $(N=645)$.

\begin{tabular}{|c|c|c|c|c|c|c|}
\hline \multirow[t]{3}{*}{ Variables } & \multicolumn{2}{|c|}{ Anxiety symptoms } & \multirow[b]{3}{*}{$t / Z$} & \multicolumn{2}{|c|}{ Depressive symptoms } & \multirow[b]{3}{*}{$t / Z$} \\
\hline & Yes & No & & Yes & No & \\
\hline & \multicolumn{2}{|c|}{ M (SD)/M (P25, P75) } & & \multicolumn{2}{|c|}{ M (SD)/M (P25, P75) } & \\
\hline \multicolumn{7}{|l|}{ FES-CV } \\
\hline Cohesion & $7.05(2.25)$ & $8.12(1.35)$ & $6.76^{\star \star \star}$ & $6.64(2.31)$ & $8.20(1.28)$ & $9.09^{\star \star \star}$ \\
\hline Expressiveness & $5.34(1.79)$ & $5.97(1.49)$ & $4.66^{\star \star \star}$ & $4.90(1.78)$ & $6.11(1.42)$ & $8.57^{\star \star \star}$ \\
\hline Conflict & $2(1.3)$ & $3(2.5)$ & $-6.12^{\star \star \star}$ & $2(1.3)$ & $3(2.5)$ & $-6.12^{\star \star \star}$ \\
\hline GSES & $2.53(0.56)$ & $2.76(0.55)$ & $5.15^{\star \star \star}$ & $2.47(0.54)$ & $2.76(0.55)$ & $6.26^{\star \star \star}$ \\
\hline
\end{tabular}

${ }^{* * *} P<0.001$. FES-CV, The Family Environment Scale-Chinese Version; GSES, The General Self-Efficacy Scale.

TABLE 3 | Correlations between the factors of different scales $(N=645)$.

\begin{tabular}{|c|c|c|c|c|c|c|}
\hline Variables & Cohesion & Expressiveness & Conflict & General self-efficacy & Anxiety symptoms & Depressive symptoms \\
\hline Cohesion & - & & & & & \\
\hline Expressiveness & $0.44^{\star \star \star}$ & - & & & & \\
\hline Conflict & $-0.32^{\star \star \star}$ & $-0.14^{\star \star}$ & - & & & \\
\hline General self-efficacy & $0.24^{\star \star \star}$ & $0.15^{\star \star \star}$ & $-0.11^{\star \star}$ & - & & \\
\hline Anxiety symptoms & $-0.31^{\star \star \star}$ & $-0.23^{\star \star \star}$ & $0.29^{\star \star \star}$ & $-0.25^{\star \star \star}$ & - & \\
\hline Depressive symptoms & $-0.38^{\star \star \star}$ & $-0.30^{\star \star \star}$ & $0.25^{\star \star \star}$ & $-0.25^{\star \star \star}$ & $0.72^{\star \star \star}$ & - \\
\hline
\end{tabular}

${ }^{\star *} P<0.01 ;{ }^{* *} P<0.001$.

the family environment, were more likely to show anxiety and depressive symptoms during the epidemic.

Notably, in this present study, the relationship between the family environment and the symptoms of anxiety and depression reveals that the family environment can, directly and indirectly, affect the emotions of medical staff during an epidemic. The family environment can significantly predict the emergence of anxiety and depressive symptoms directly, which is consistent with previous results. For example, some studies found that there was a correlation between cohesion in the family environment and depression in family members (Burnett et al., 2017); families with high cohesion, which have high levels of family support and ties, likely reduce depression (Park et al., 2018; Cano et al., 2020). In contrast, low family cohesion and conflict between parents increased the risk of depression and anxiety in family members (Park et al., 2018; Cano et al., 2020). In families with a high degree of cohesion, individuals can get more psychological help and emotional support within the family (Birgisdóttir et al., 2019), so that the psychological pressure can be appropriately relieved. Positive emotional expression within the family can prevent suppression of inner feelings and buffer internal conflicts, especially in the face of stressful events. In contrast, negative emotional expression and low emotional expression within the family are associated with higher anxiety and depression (Luebbe and Bell, 2014; Park et al., 2018). In a high-conflict family, family members are prone to conflict between each other, leading to anxiety. Therefore, the results in this study support the hypothesis that the family environment can influence the emotional state of the family members and that a negative family environment is a psychological risk factor for the rising emotional distress of the medical staff during an epidemic.
Additionally, the influence of the medical staff's family environment on their symptoms of anxiety and depression during the COVID-19 epidemic is partly through the role of self-efficacy, which means self-efficacy plays a critical role in mediating the effect of family environment on symptoms of anxiety and depression. Indeed, previous studies supported that self-efficacy had a protective effect on mental health (Bandura, 2012) and played a vital role in the regulation of stress (Bandura et al., 2003). High self-efficacy was related to better psychological adjustment (Bandura, 2012) and lower emotional distress (Benight and Harper, 2002). Individuals with high selfefficacy had positive expectations and beliefs, had successful experiences, generated positive emotions, and were more likely to seek psychological support to modulate their emotions when facing stressful situations (Tsang et al., 2012). A bad family environment can reduce an individual's self-confidence and ability (Hemati et al., 2020). Self-efficacy is the embodiment of such confidence and ability (Tang et al., 2019). That is to say, the family environment affects self-efficacy by affecting people's self-confidence and ability, thus affecting individuals' behavioral patterns and emotional responses to stress (Tsang et al., 2012). For example, a medical worker with a good family environment has confidence in the success of the fight against the epidemic and also believes that he is capable of doing his job, which will ease his fear of the epidemic and anxiety about the high-risk work of infection. Self-efficacy played a partial mediating role between the family environment and symptoms of anxiety and depression, indicating the existence of other variables between them. Future studies should, therefore, include other relevant variables that are likely involved in the relationship between the family environment and negative emotions. This 

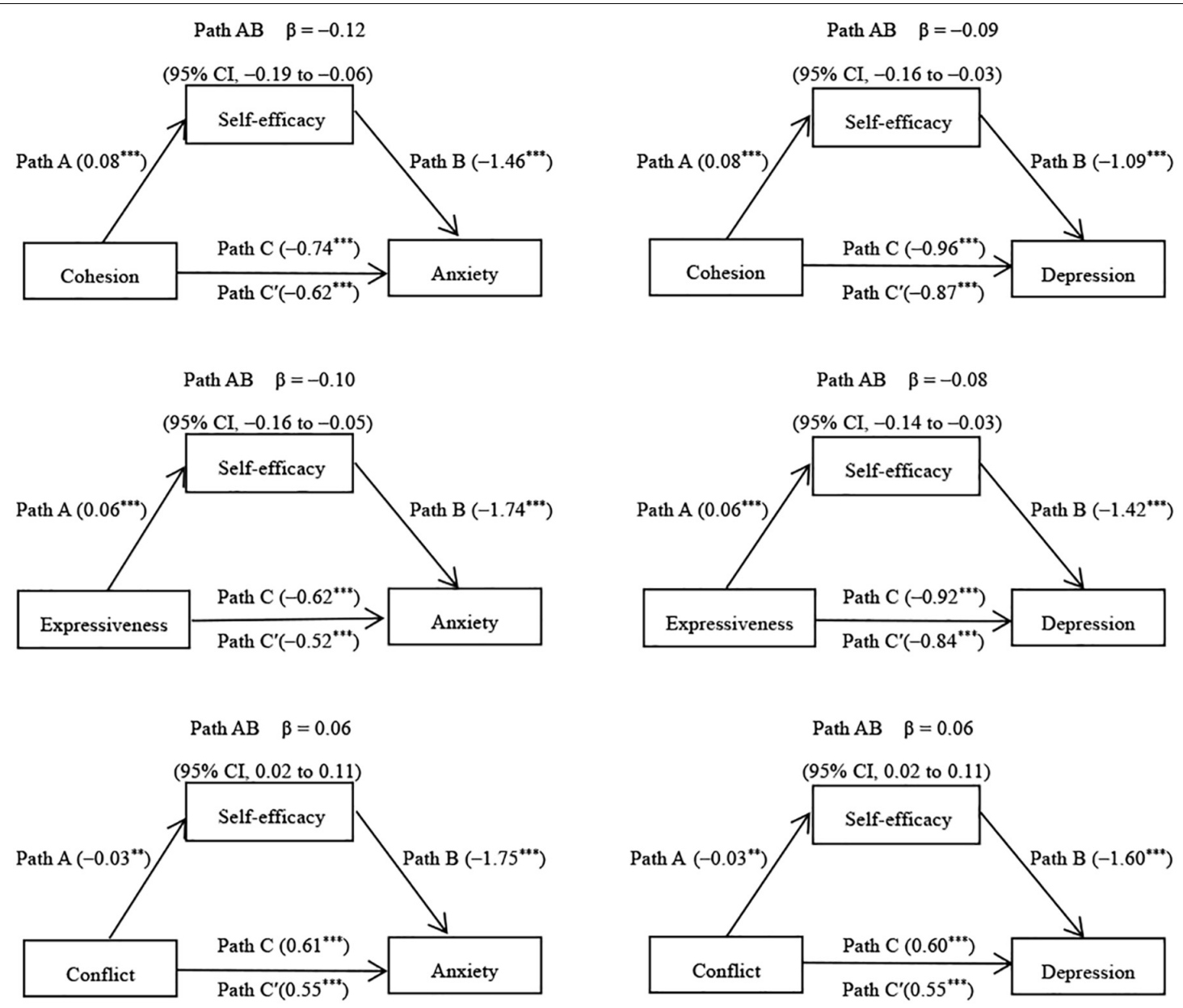

FIGURE 1 | Mediation effects of self-efficacy in the relationship between family environment and the symptoms of anxiety and depression $(N=645) .{ }^{* *} P<0.01$; ${ }^{\star * *} P<0.001$.

study indicates that adjusting self-efficacy is a meaningful way to regulate the anxiety and depressive symptoms of medical staff during an epidemic.

Because of the close correlation between the family environment and the symptoms of anxiety and depression of medical staff during an epidemic, we need to pay more attention to psychological assistance for medical staff from the perspective of their family situation. When providing psychological assistance to medical staff during the epidemic, we should not only focus on the medical staff but also care about their family members and family relations. By improving the family environment and increasing the active support of the family, their emotional problems can be effectively alleviated (Mohindra et al., 2020). The focus of the medical staff's treatment of family relations should be to enhance the intimacy between family members, increase their interaction, encourage them to talk to each other, resolve the family conflicts in time, and create a good family atmosphere. Based on the results of this study, we propose the following suggestions for medical staff. First, we suggest that medical staff should have time to communicate with their families and that they should be encouraged to share their feelings with family members and get their support and encouragement. For example, they should be encouraged to record their routines in the hospital and share them with their families (Chen et al., 2020). The hospital or isolation point shall provide relevant communication conditions and equipment for this purpose. Second, during the epidemic period, the staff of the relevant departments of the hospital should be aware of the difficulties existing in the family of medical staff, and they should guide these staff members and help them solve those problems to avoid family conflicts. Third, the family members of medical staff should be aware of the mental health issues of the staff member. Family safety plays the most important role in reducing the pressure of medical staff during the epidemic (Cai et al., 2020). Therefore, the staff members should stay connected with their families through WeChat, SMS, and other apps to understand their health status, which will help lessen the negative mental state of the medical staff during the COVID-19 pandemic outbreak. These Suggestions can bring medical staff closer to their families, have more emotional communication, and reduce family conflicts. With the implementation of these measures, the medical staff's sense of self-efficacy will also be improved. 
Besides, our results suggest that improving self-efficacy will help to alleviate the anxiety and depressive symptoms of medical staff during the COVID-19 outbreak. Manipulating self-efficacy is an important way to prevent mental health problems when dealing with stress (Schönfeld et al., 2019). Previous studies have focused on the effects of self-efficacy on the mental health and work quality of medical staff (Amiri et al., 2019; Tang et al., 2019), and it suggested that necessary interventions should be implemented to improve the self-efficacy of medical staff. In the prevention and control of COVID-19, medical staff is faced with two main difficulties. On the one hand, medical staff has heavy work tasks, great pressure, high risk of infection, and lack of support (Spoorthy et al., 2020). On the other hand, most of the medical staff are required to be isolated in hospitals or isolation points. Their families will face more prominent problems (Mohindra et al., 2020). Some positive motivation factors can boost morale and improve the self-efficacy of medical staff, such as family and social support, positive example, recognition, and appreciation from others, successful experience, self-identity (Spoorthy et al., 2020). Positive feedback and encouragement from others could also effectively improve self-efficacy (Bandura, 1997; Zinken et al., 2008; Brown et al., 2012). The pre-job training, encouragement from colleagues and family, affirmation from patients and society, and sufficient material support were all helpful ways to improve the self-efficacy of medical staff during the COVID-19 outbreak. Medical staff in a good family environment can get better family support. The support reduces the sense of uneasiness caused by isolation, and improve self-efficacy, increase work confidence, improve work efficiency and quality, and reduce the negative emotions caused by epidemic infection.

It has been reported that the mental health status of Chinese medical staff is poor (Zhou et al., 2018), and they are exposed to immense workplace pressure and face complex doctor-patient relationships. The reason lies in the contradictions in the current medical system reform in China, such as the uneven distribution of medical resources (Lu et al., 2019), the disequilibrium between health care needs and medical development (Zhou et al., 2018), and the imperfection of the medical system (Ta et al., 2020). During an epidemic period, protecting the mental health of the medical staff would benefit their health as well as the control of the epidemic worldwide (Kang et al., 2020). The National Health Commission of China has published a national guideline of psychological crisis intervention for COVID-19, which is guided for the protection of the mental health of the medical staff (Kang et al., 2020). However, the family environment is particularly important to the mental health of the medical staff, and self-efficacy plays an important role in

\section{REFERENCES}

Amiri, M., Vahedi, H., Mirhoseini, S. R., Eghtesadi, A. R., and Khosravi, A. (2019). Study of the relationship between self-efficacy, general health and burnout among iranian health workers. Osong Public Health Res. Perspect. 10, 359-367. doi: 10.24171/j.phrp.2019.10.6.06

Bai, Y., Lin, C. C., Lin, C. Y., Chen, J. Y., Chue, C. M., and Chou, P. (2004). Survey of stress reactions among health care workers involved with the regulating the relationship between them. Appropriate guidelines should be issued nationally to improve the family environment of the medical staff and for the improvement of their selfefficacy.

There are some limitations to the current study that need to be addressed. First, there are limitations to the method of sampling. Sampling bias may have occurred by using a convenient sampling method. Second, we have a small sample size, and all participants are from Beijing, so the research participants in this study may not be sufficiently representative of the population we are interested in studying, which may limit the conclusion of research results. Third, online questionnaire surveys cannot observe the participants' answering process, there is the possibility of random answer and perfunctory answer, cannot guarantee the complete authenticity of data. Fourth, we did not measure other potential confounding variables that may exist between the family environment and the emotional state of medical staff during the COVID-19 outbreak. Finally, the researchers are all medical staff, and the design of the survey may be more based on clinical observation. In the future, the research design can be combined with clinical observation and the existing theoretical framework.

\section{CONCLUSION}

In the current study, we found that the anxiety and depressive symptoms of medical staff during the COVID-19 outbreak was closely related to their family environment, and their self-efficacy regulated the relationship between them. This study provides a new direction for the psychological intervention in medical staff during the epidemic that mainly focuses on improving their family environment and their self-efficacy.

\section{DATA AVAILABILITY STATEMENT}

The raw data supporting the conclusions of this article will be made available by the authors, without undue reservation, to any qualified researcher.

\section{AUTHOR CONTRIBUTIONS}

$\mathrm{NH}$ contributed to the manuscript writing. J-XC, YL, and S-SH contributed to the conception and designed the work. YL, L-LW, Y-YW, and LY contributed to the critical revision of the article. All authors contributed to the article and approved the submitted version.

SARS outbreak. Psychiatr. Serv. 55, 1055-1057. doi: 10.1176/appi.ps.55.9. 1055

Bandura, A. (1997). Self-Efficacy in Changing Societies. New York, NY: Cambridge University Press.

Bandura, A. (2012). On the functional properties of perceived self-efficacy revisited. J. Manage. 38, 9-44. doi: 10.1177/0149206311410606

Bandura, A., Caprara, G. V., Barbaranelli, C., Gerbino, M., and Pastorelli, C. (2003). Role of affective self-regulatory efficacy in diverse spheres of 
psychosocial functioning. Child Dev. 74, 769-782. doi: 10.1111/1467-8624. 00567

Bandura, A., Reese, L., and Adams, N. E. (1982). Microanalysis of action and fear arousal as a function of differential levels of perceived self-efficacy. J. Pers. Soc. Psychol. 43, 5-21. doi: 10.1037//0022-3514.43.1.5

Benight, C. C., and Harper, M. L. (2002). Coping self-efficacy perceptions as a mediator between acute stress response and long-term distress following natural disasters. J. Traumat. Stress 15, 177-186. doi: 10.1023/A:1015295025950

Birgisdóttir, D., Bylund Grenklo, T., Nyberg, T., Kreicbergs, U., Steineck, G., and Fürst, C. J. (2019). Losing a parent to cancer as a teenager: family cohesion in childhood, teenage, and young adulthood as perceived by bereaved and non-bereaved youths. Psycho Oncol. 28, 1845-1853. doi: 10.1002/pon.5163

Brown, A. D., Dorfman, M. L., Marmar, C. R., and Bryant, R. A. (2012). The impact of perceived self-efficacy on mental time travel and social problem solving. Conscious. Cogn. 21, 299-306. doi: 10.1016/j.concog.2011.09.023

Burnett, A. C., Lee, K. J., Cheong, J. L., Luca, C. R., Roberts, G., Wood, S. J., et al. (2017). Family functioning and mood and anxiety symptoms in adolescents born extremely preterm. J. Dev. Behav. Pediatr. 38, 39-48. doi: 10.1097/DBP. 0000000000000368

Cai, H., Tu, B., Ma, J., Chen, L., Fu, L., Jiang, Y., et al. (2020). Psychological impact and coping strategies of frontline medical staff in Hunan between January and March 2020 during the outbreak of coronavirus disease 2019 (COVID-19) in Hubei, China. Med. Sci. Monit. 26:e924171. doi: 10.12659/MSM.924171

Caldwell, K., Harrison, M., Adams, M., and Triplett, N. T. (2009). Effect of pilates and taiji quan training on self-efficacy, sleep quality, mood, and physical performance of college students. J. Bodyw. Mov. Ther. 13, 155-163. doi: 10. 1016/j.jbmt.2007.12.001

Cano, M. Á, Castro, F. G., De La Rosa, M., Amaro, H., Vega, W. A., Sánchez, M., et al. (2020). Depressive symptoms and resilience among hispanic emerging adults: examining the moderating effects of mindfulness, distress tolerance, emotion regulation, family cohesion, and social support. Behav. Med. 46, 245-257. doi: 10.1080/08964289.2020.1712646

Chen, Q., Liang, M., Li, Y., Guo, J., Fei, D., Wang, L., et al. (2020). Mental health care for medical staff in China during the COVID-19 outbreak. Lancet Psychiatry 7, e15-e16. doi: 10.1016/S2215-0366(20)30078-X

Cheng, Y., Zhang, L., Wang, F., Zhang, P., Ye, B., and Liang, Y. (2017). The effects of family structure and function on mental health during China's transition: a cross-sectional analysis. BMC Fam. Pract. 18:59. doi: 10.1186/s12875-0170630-4

Cieslak, R., Benight, C. C., and Caden Lehman, V. (2008). Coping self-efficacy mediates the effects of negative cognitions on posttraumatic distress. Behav. Res. Ther. 46, 788-798. doi: 10.1016/j.brat.2008.03.007

Cybulski, M., Cybulski, L., Krajewska-Kulak, E., and Cwalina, U. (2017). The level of emotion control, anxiety, and self-efficacy in the elderly in Bialystok, Poland. Clin. Intervent. Aging. 12, 305-314. doi: 10.2147/CIA.S128717

Fosco, G. M., Van Ryzin, M. J., Connell, A. M., and Stormshak, E. A. (2016). Preventing adolescent depression with the family check-up: examining family conflict as a mechanism of change. J. Fam. Psychol. 30, 82-92. doi: 10.1037/ fam0000147

Haj-Yahia, M. M., Hassan-Abbas, N., Malka, M., and Sokar, S. (2019). Exposure to family violence in childhood, self-efficacy, and posttraumatic stress symptoms in young adulthood. J. Interpers. Violence 886260519860080. doi: 10.1177/ 0886260519860080

Harris, C. A., and Zakowski, S. G. (2003). Comparisons of distress in adolescents of cancer patients and controls. Psycho Oncol. 12, 173-182. doi: 10.1002/pon.631

Hemati, Z., Abbasi, S., Oujian, P., and Kiani, D. (2020). Relationship between parental communication patterns and self-efficacy in adolescents with parental substance abuse. Iran. J. Child Neurol. 14, 49-56.

Ho, S. M., Kwong-Lo, R. S., Mak, C. W., and Wong, J. S. (2005). Fear of severe acute respiratory syndrome (SARS) among health care workers. J. Consult. Clin. Psychol. 73, 344-349. doi: 10.1037/0022-006X.73.2.344

Huang, J. Z., Han, M. F., Luo, T. D., Ren, A. K., and Zhou, X. P. (2020). [Mental health survey of 230 medical staff in a tertiary infectious disease hospital for COVID-19]. Zhonghua Lao Dong Wei Sheng Zhi Ye Bing Za Zhi 38, 192-195. doi: 10.3760/cma.j.cn121094-20200219-00063

Huang, M., Liu, Y., Wang, J., Mo, L., Wang, Y., Chen, L., et al. (2019). High rates of depression anxiety and suicidal ideation among inpatients in general hospital in China. Int. J. Psychiatry Clin. Pract. 23, 99-105. doi: 10.1080/13651501.2018. 1539179

Jiang, X., Deng, L., Zhu, Y., Ji, H., Tao, L., Liu, L., et al. (2020). Psychological crisis intervention during the outbreak period of new coronavirus pneumonia from experience in Shanghai. Psychiatry Res. 286:112903. doi: 10.1016/j.psychres. 2020.112903

Kanfer, R., and Zeiss, A. M. (1983). Depression, interpersonal standard setting, and judgments of self-efficacy. J. Abnorm. Psychol. 92, 319-329. doi: 10.1037//0021843X.92.3.319

Kang, L., Li, Y., Hu, S., Chen, M., Yang, C., Yang, B. X., et al. (2020). The mental health of medical workers in Wuhan, China dealing with the 2019 novel coronavirus. Lancet Psychiatry 7:e14. doi: 10.1016/S2215-0366(20)30047-X

Kang, P., Lv, Y., Hao, L., Tang, B., Liu, Z., Liu, X., et al. (2015). Psychological consequences and quality of life among medical rescuers who responded to the 2010 Yushu earthquake: a neglected problem. Psychiatry Res. 230, 517-523. doi: 10.1016/j.psychres.2015.09.047

Kroenke, K., Spitzer, R. L., and Williams, J. B. (2001). The PHQ-9: validity of a brief depression severity measure. J. Gen. Int. Med. 16, 606-613. doi: 10.1046/j.15251497.2001.016009606.x

Lai, J., Ma, S., Wang, Y., Cai, Z., Hu, J., Wei, N., et al. (2020). Factors associated with mental health outcomes among health care workers exposed to coronavirus disease 2019. JAMA Netw. Open 3:e203976. doi: 10.1001/jamanetworkopen. 2020.3976

Lu, C., Zhang, Z., and Lan, X. (2019). Impact of China's referral reform on the equity and spatial accessibility of healthcare resources: a case study of Beijing. Soc. Sci. Med. 235:112386. doi: 10.1016/j.socscimed.2019.112386

Luebbe, A. M., and Bell, D. J. (2014). Positive and negative family emotional climate differentially predict youth anxiety and depression via distinct affective pathways. J. Abnorm. Child Psychol. 42, 897-911. doi: 10.1007/s10802-0139838-5

Mahmoudi, A. (2012). Effect of self-esteem and self-efficacy in family dynamics. Proc. Soc. Behav. Sci. 46, 53-56. doi: 10.1016/j.sbspro.2012.05.066

Mohindra, R., Ravaki, R., Suri, V., Bhalla, A., and Singh, S. M. (2020). Issues relevant to mental health promotion in frontline health care providers managing quarantined/isolated COVID19 patients. Asian J. Psychiatr. 51:102084. doi: 10.1016/j.ajp.2020.102084

Moos, R. H., and Moos, B. S. (1994). Family Environment Scale Manual, third Edn. Palo Alto, CA: Consulting Psychologists Press.

Park, Y. Y., Jeong, Y. J., Lee, J., Moon, N., Bang, I., Kim, H., et al. (2018). The influence of family adaptability and cohesion on anxiety and depression of terminally ill cancer patients. Support. Care Cancer 26, 313-321. doi: 10.1007/ s00520-017-3912-4

Phillips, M. R., West, C. L., Shen, Q., and Zheng, Y. (1998). Comparison of schizophrenic patients' families and normal families in China, using Chinese versions of FACES-II and the family environment scales. Fam. Process 37, 95-106. doi: 10.1111/j.1545-5300.1998.00095.x

Poulin, J., Deng, R., Ingersoll, T. S., Witt, H., and Swain, M. (2012). Perceived family and friend support and the psychological well-being of American and Chinese elderly persons. J. Cross Cult. Gerontol. 27, 305-317. doi: 10.1007/s10823-0129177-y

Preacher, K. J., and Hayes, A. F. (2004). SPSS and SAS procedures for estimating indirect effects in simple mediation models. Behav. Res. Methods Instrum. Comput. 36, 717-731. doi: 10.3758/bf03206553

Raven, J., Wurie, H., and Witter, S. (2018). Health workers' experiences of coping with the Ebola epidemic in Sierra Leone's health system: a qualitative study. BMC Health Serv. Res. 18:251. doi: 10.1186/s12913-018-3072-3

Sachs-Ericsson, N., Medley, A. N., Kendall-Tackett, K., and Taylor, J. (2011). Childhood abuse and current health problems among older adults: the mediating role of self-efficacy. Psychol. Violence 1, 106-120. doi: 10.1037/ a0023139

Schönfeld, P., Brailovskaia, J., Zhang, X. C., and Margraf, J. (2019). Self-efficacy as a mechanism linking daily stress to mental health in students: a three-wave crosslagged study. Psychol. Rep. 122, 2074-2095. doi: 10.1177/0033294118787496

Schwarzer, R. (1995). Measuring optimistic self-beliefs: a Chinese adaptation of the general self-efficacy scale. Psychologia 38:174.

Sebastian, V. (2013). A theoretical approach to stress and self-efficacy. Proc. Soc. Behav. Sci. 78, 556-561. doi: 10.1016/j.sbspro.2013.04.350 
Shacham, M., Hamama-Raz, Y., Kolerman, R., Mijiritsky, O., Ben-Ezra, M., and Mijiritsky, E. (2020). COVID-19 factors and psychological factors associated with elevated psychological distress among dentists and dental hygienists in israel. Int. J. Environ. Res. Public Health 17:2900. doi: 10.3390/ijerph17082900

Spitzer, R. L., Kroenke, K., Williams, J. B., and Löwe, B. (2006). A brief measure for assessing generalized anxiety disorder: the GAD-7. Arch. Int. Med. 166, 1092-1097. doi: 10.1001/archinte.166.10.1092

Spoorthy, M. S., Pratapa, S. K., and Mahant, S. (2020). Mental health problems faced by healthcare workers due to the COVID-19 pandemic-a review. Asian J. Psychiatr. 51:102119. doi: 10.1016/j.ajp.2020.102119

Ta, Y., Zhu, Y., and Fu, H. (2020). Trends in access to health services, financial protection and satisfaction between 2010 and 2016: has China achieved the goals of its health system reform. Soc. Sci. Med. 245:112715. doi: 10.1016/j. socscimed.2019.112715

Tang, N., Han, L., Yang, P., Zhao, Y., and Zhang, H. (2019). Are mindfulness and self-efficacy related to presenteeism among primary medical staff: a cross-sectional study. Int. J. Nurs. Sci. 6, 182-186. doi: 10.1016/j.ijnss.2019. 03.004

Tsang, S. K., Hui, E. K., and Law, B. C. (2012). Self-efficacy as a positive youth development construct: a conceptual review. ScientificWorldJournal 2012:452327. doi: 10.1100/2012/452327

Wang, C., Horby, P. W., Hayden, F. G., and Gao, G. F. (2020). A novel coronavirus outbreak of global health concern. Lancet 395, 470-473. doi: 10.1016/S01406736(20)30185-9

Wang, C., Hu, Z., and Liu, Y. (2001). Evidences for reliability and validity of chinese version of general self-efficacy scale. Chin. J. Appl. Psychol. 7, 37-40.

Wang, W., Bian, Q., Zhao, Y., Li, X., Wang, W., Du, J., et al. (2014). Reliability and validity of the Chinese version of the patient health questionnaire (PHQ9) in the general population. Gen. Hosp. Psychiatry 36, 539-544. doi: 10.1016/j. genhosppsych.2014.05.021
Wang, X. D., Wang, X. L., and Ma, H. (1999). Rating Scales for Mental Health (Updated Version). Beijing: Editorial Board of Chinese Mental Health Journal.

Xiang, Y. T., Yang, Y., Li, W., Zhang, L., Zhang, Q., Cheung, T., et al. (2020). Timely mental health care for the 2019 novel coronavirus outbreak is urgently needed. Lancet Psychiatry 7, 228-229. doi: 10.1016/S2215-0366(20)30046-8

Yap, M. B., and Jorm, A. F. (2015). Parental factors associated with childhood anxiety, depression, and internalizing problems: a systematic review and metaanalysis. J. Affect. Disord. 175, 424-440. doi: 10.1016/j.jad.2015.01.050

Yap, M. B., Pilkington, P. D., Ryan, S. M., and Jorm, A. F. (2014). Parental factors associated with depression and anxiety in young people: a systematic review and meta-analysis. J. Affect. Disord. 156, 8-23. doi: 10.1016/j.jad.2013.11.007

Yıldırım, M., and Güler, A. (2020). COVID-19 severity, self-efficacy, knowledge, preventive behaviors, and mental health in Turkey. Death Stud. 1-8. doi: 10. 1080/07481187.2020.1793434

Zhou, C., Shi, L., Gao, L., Liu, W., Chen, Z., Tong, X., et al. (2018). Determinate factors of mental health status in Chinese medical staff: a cross-sectional study. Medicine 97:e0113. doi: 10.1097/MD.0000000000010113

Zinken, K. M., Cradock, S., and Skinner, T. C. (2008). Analysis system for selfefficacy training (ASSET). assessing treatment fidelity of self-management interventions. Patient Educ. Couns. 72, 186-193. doi: 10.1016/j.pec.2008.04.006

Conflict of Interest: The authors declare that the research was conducted in the absence of any commercial or financial relationships that could be construed as a potential conflict of interest.

Copyright (c) $2020 \mathrm{Hu}, \mathrm{Li}, \mathrm{He}$, Wang, Wei, Yin and Chen. This is an open-access article distributed under the terms of the Creative Commons Attribution License (CC BY). The use, distribution or reproduction in other forums is permitted, provided the original author(s) and the copyright owner(s) are credited and that the original publication in this journal is cited, in accordance with accepted academic practice. No use, distribution or reproduction is permitted which does not comply with these terms. 